\title{
Semantic Groups of Vocabulary in Sports Reports
}

\author{
Gevorg Barseghyan \\ Yerevan State University
}

\begin{abstract}
Nowadays sports as a separate component of social life includes a great many varieties which enable millions of sportsmen and fans to communicate with one another. Thorough research is carried out on various aspects of sport: from the philosophy of sports to exquisite psychological observations of individual sportmen. Thus the study of the forms and the style of sports reports as well as their linguostylistic peculiarities has become an imperative. The aim of our research is to reveal the characteristic features of sports reports with reference to the vocabulary used, namely - the semantic groups most frequently occurring in sports speech.
\end{abstract}

Key words: semantic groups of vocabulary, semantic similarity and difference, synonymy, contextual synonyms, antonymy.

\section{Introduction}

It has been established that words can generally be grouped thematically but their classification according to their semantic similarities and differences is also of utmost importance. When one aims at communicating on a concrete topic it is always very important to consider the extralinguistic relations of the things meant in real life. On the other hand, typical speech situations often presuppose the use of words with common contextual association in the same semantic group.

One of the essential principles of the investigation of vocabulary is the classification of words based on the criterion of their semantic similarity which exposes the synonymic relations between lexical elements. The absence of a 
conclusive solution to the problem of synonymy basically consists in the controversy of approaches to the problem of the criterion of semantic equivalence and the ways meaning is conveyed in language (Cruse 2000). Without going into the details of the discussion along these lines we however believe that two separate words cannot semantically be exactly the same (Bloomfield 1984) (except for very rare cases of terminological units), particularly if the meaning of a lexical unit is viewed from the point of view of the complex correlation of its literal meaning (denotation) and the emotional weight of the word (connotation).

We shall now turn to the concrete object of our study proceeding from our preliminary observations which reveal a rather frequent use of synonyms in sub-styles of public writing and newspaper language including sports reports and different publications on sports. Since any reported news aims to make an effect on the public, the application of various means of reporting, including synonyms, calls for additional attention to the problem.

\section{Synonymic Pairs in Sorts Reports}

To avoid monotony as well as unnecessary repetition of words and expressions in sports reports, reporters turn to synonyms which, emphasizing different aspects and shades of meaning, provide the presented news with diversity and more impressiveness. Our observations confirm that although the phenomenon of synonymy is first and foremost associated with the notion of semantic relations between words, however, in sports reports (and in general) semantic equivalence occurs also between word-groups and even sentences. As far as the interchangeability of synonyms is concerned, we have to bear in mind that this greatly depends on the context.

Synonyms can emerge in conversational style, particularly in interviews and direct addresses. Everything depends on the personality of the speaker, his/her ability of figurative thinking. In this case, conversational forms can be applied parallel to the literary ones. Thus, for example, 
"At the beginning of the season everybody said that our veterans will get out of breath a month later, will not be able to play”.

(Sport Europe, n.46/99, p. 47)

The close study of the context above shows quite clearly that the wordgroups get out of breath and will not be able to play are not synonyms in the proper sense of the term, though the idea expressed by both of them is the same. The impact produced by the context is provided by the clash of the literary neutral word-group will not be able to play and the colloquial get out of breath. In the next passage the situation is more or less the same:

"Now my hand aches terribly, it became tired and weak during the wrestling, and thus I want to finish, to put an end. I don't have power any more".

(Sport, 7/96, p.17)

Here the use of the qualitative adjective weak following the word-group became tired, and then the advancement of the context to present the occurrence of another pair (finish - to put an end) disappoint the reader and create an atmosphere of pity and grief for the beloved wrestler of the fans whose physical strength and powers have abandoned him. Due to this particular choice and arrangement of the elements of both synonymic groups (become tired - weak; finish-put an end) a kind of synonymic gradation arises which intensifies the impressive power of the context. The fact that in both pairs the first components are from the neutral layer of the vocabulary (become tired and finish) requires particular attention. This use of synonymic pairs is, of course directly connected with the positive attitude of the speaker towards the sportsman and his/her figurative thinking as well.

Elements of the same group of synonyms help to make a more detailed picture of the given phenomena. Let's look into the passage below. 
"Five minutes later the Yugoslavians left the stadium. And Belov sitting on the bench was bandaging his painful, fractured leg. He rose slowly, when other teams appeared in the stadium. But the audience didn't leave and disregard him. Who shouldn't leave alone unnotable. The team was defeated but it played encouraged, brightly during all the tournament and left proudly, as a winner. It devoted everything; its emotions and sports wickedness and its latest power for its victory and the hall accompanied it standing".

(Olympic Moscow 1980, p. 23)

The synonyms used in the extract adduced above not only make the speech more expressive, but also convey detailed information about everything that happened after and before the match, i.e. they help the speaker be more exact in his description of the events.

After a very difficult and persistent fight, Belov got injured. Therefore, the reporter used not only the adjective painful, but also fractured, that speak of the severity of the injury and the strong will of the sportsman. He did not leave the arena. When other teams appeared in the stadium, "he rose"signaling not only the end of the fearless fight, but also the end of all those unparalleled, exceptional and truly memorable moments of the sports feats that the sportsman had previously presented to millions of people. Hence, sports fans would not dream of leaving or disregarding him. Though the team was defeated, Belov showed an encouraged and bright performance throughout the tournament. Otherwise stated, he invested all his physical and mental strength, as well as his professional talent of a sportsman in it. That's why the phrase "Belov left the stadium not only with his head up" used by the reporter in the larger context of his sports news is intended to emphasize the fact that Belov excels everyone and leaves as a true winner. But he receives such descriptions because he and his team have devoted all their emotions and passion, sports wickedness and skills and, last but not least, their latest power to win.

It is evident, that without the use of synonyms the reporter could not have 
conveyed the inner drama and the tension of the match and the given sportsman. Neither could the reporter enhance the idea of his strong will to win, his hard work of long years, his professional performance, and at the same time the unavailability and inaccessibility of the victory. And again, in this case, too, the use of the semantic groups painful - fractured, leave - disregard, encouraged brightly, its emotions - sports wickedness - its latest power creates rows of semantic equivalence through which the pride and devotion of the sportsman and his team are emphasized.

In colloquial style which is more often reflected in dialogues, one can also meet emotive and expressive synonyms such as shoot - kick, win - gain, notable - famous, powerful - strong, wrestler - fighter, sprinter - dashman, etc. These elements demonstrate the evaluative attitude of the speaker and provide detailed information about the sport event.

It should be noted that even the slightest semantic differences play a very important role from a stylistic point of view, meanwhile contributing to the application of most diverse and unusual forms of thoughts. Otherwise stated, the reporter enriches his statements with various figurative expressions without introducing unnecessary repetitions into his speech.

Thus, synonyms differ in form, but express the same general meaning despite the small stylistic differences. The "neutral" word usually contained in any synonymic group acts as the main word, while others offer differences in additional expressive-emotional-evaluative nuances. The study of our material reveals that the use of synonymic rows like to think - to judge - to ponder, known - famous - outstanding, fearless - frightless - riskful, shoot - kick - fire, etc. is rather frequent in sports reports. The extract below is a case in point.

"His ability to dribble, kick and shoot with both feet is making him a contrast nuisance".

(Footballasia, June 2003, p. 38)

The word shoot, which in the Oxford Advanced Dictionary of Current English is defined as "make a shot at scoring a goal", in the given example is 
obviously used to intensify the meaning of kick (hit with the foot)', to enhance the impression achieved by kick in the context, as well as reveal the attitude of the speaker towards the sportsman he/she introduces to the readers. The function of intensifying is also present in the following passage from a sport report where the word crush (pressing to cause to lose shape) is obviously used figuratively to intensify the meaning of must be broken down and make the impact of the context much stronger.

"The resistance must be broken down, crushed, otherwise will be impossible to resist their suppression".

(SporT Vision, N 121/January 1998, p. 23)

\section{The Role of Antonyms in Sports Reports}

The linguostylistic value of sports reports is enriched by the use (though not very frequent) of antonymous elements which have long been established as a regular and very natural feature of language (Gao 2014). Just like synonymy, for antonymy as well the presence of a common feature is a must, only in this case it serves as basis of opposition. It is well known that the stylistic value of antonyms is demonstrated in opposition, i.e. in semantic polarity (Girunyan 2009). It is important to note that in antonymic semantic relations the contrast is based on only one feature, and the component of connotation, i.e. the additional expressive-emotional-evaluative overtones are not taken into consideration. In speech, they can oppose each other in different ways. In sports reports the opposition represented in speech is very often absolute. In this case the antonymic pairs share a characteristic which by some linguists is described as definitive in understanding the antonymic relations in the pair. This means that each of the members of the antonymic pair denotes this or that degree of some property which can be intensified in opposite directions (e.g. high-low, easy-difficult, short-long, fast-slow, to become strong-to become week, to climb-to come down, etc.).

It is obvious that antonyms are fewer in language than synonyms, since it is simply difficult to find opposite meanings for many words used in a language 
(e.g. point, ball, goal, whistle, etc.). Naturally, the majority of pronouns, numerals, conjunctions, connectives, exclamations, etc. do not form antonym pairs.

The use of antonym pairs in sports reports avails the reporter of the opportunity to present a thorough description of the sport event. Thus, for example,

"The skiers were rising and coming down through the bosom of the mountain with the greatest intension to reach the winding. The power must be kept in order to overcome the height. The fast skate run of the sportsmen is opposed to the cars slow run, the audience slow walk is incomparable with their studious movements".

(Panorama, N 1-2 July, 1996, p. 45)

In this extract, with the help of the antonym pairs rise-come down, fastslowly, slow-studious the reporter draws the attention of the reader to the track followed by the skiers. No victory is easily achieved. It takes the utmost concentration of all efforts so that the easier section of the road, the winding, gets closer. To indicate the high speed of the run of the skiers, the reporter compares, or rather, contrasts it with the slow movement of the cars (though in reality, cars do not move slowly). Still, the reporter considers the comparison insufficient and immediately offers another contrast - the audience slow walk and the studious movements of the skiers, thereby enhancing the lasting, tense work of the sportsmen. Calmness and laziness have nothing to do with them.

It is common knowledge, that antonyms are divided into two groups language and speech antonyms (Barber 1971; Minayeva 1982; Carter 1988). Language antonyms express opposite meanings and are only linguistic realities whereas speech or contextual antonyms do not have opposite meanings at the language level. Rather, they acquire them in their concrete uses. Here are some examples. 
"Milan" showed an interesting, animated and flexible game. The opposite team was satisfied only with standard passes and polite manner".

(UEFA flash, June 2000, p. 2)

"Japan did quite well, in particular with its women's team. However they did miss some big chances, especially in the backstroke".

(Swimming, 1998, N1, p. 13)

"I felt I was winning. Let the referees think in another way. The justice won when the competition stopped because of the technics knock out".

(Boxing Magazine 1995, N32, p. 21)

In these examples, the highlighted words are obviously not antonyms at the language level. Antonymic relations between them are established only in this context. The reporter describes the performance of Milan as interesting, animated, then adding the adjective flexible he contrasts it with the rival's weak and uninteresting performance using the semantic groups "standard passes and polite manners'. The acquisition of opposite meanings is situationally bound. It is natural to think that the language could have sounded poorer, weaker and unimpressive, if, when talking about his favorite team, the reporter confined his choice to language antonyms. The same is equally true for the contextual antonym in the last example. The sportsman feels that he has an obvious advantage over his rival (...I felt I was winning) while the referees think otherwise. The sportsman's determination to win is opposed to the manners and positions of the referees.

Another contrast-based interesting stylistic structure observed in sports language is the oxymoron which combines incongruous and apparently contradictory words and meanings for a special effect (Jrbashian 1980), namely for enriching the speech with more impressive, unexpected and unusual descriptions. In fact, these elements detract each other rather than seek a union. 
Frequently occurring examples of oxymoron expressed by word combinations built with opposites are: delayed victory, aged youth, victorious defeat, innocent guilty, the honorable last place, etc.

"The participation of Spain small club "Alaves" in the final of UEFA Cup 2000/01 was major achievement, as the Spanish side returned home with a victorious defeat 5:4 in extra time from English giants 'Liverpool'.

(UEFA direct 10.02, p. 5)

Sometimes there also occur cases of oxymoron built as illogical combinations with different words and phrases such as unflammable fire, a sad victory, unaware knowledge, an implacable intimacy, etc. Sometimes one of the constituent words of this figure of speech can take a negative prefix as in unbalanced balance, unwise cleverness, unended edge line, etc.

"A silent chat was going on between the coach and the wrestler standing in the corner. Everything was an unusual, usual day for Max Fyoler".

(Sport Europe, N 43/99, p. 28)

As can be observed, the stylistic value of the oxymoron is remarkable in the context as it makes the speech more interesting and emotionally coloured meanwhile introducing a touch of intrigue into the context.

\section{Conclusion}

The investigation of the semantic groups of the vocabulary of sports reports from the viewpoint of their stylistic value brings us to the conclusion that the most widely used elements are the words similar in meaning but different in their stylistic reference. Our observations, however allow us to note that not infrequently those similarities are context-bound, as generally the semantic nuances of words arise in use, in our case in the context of presenting this or 
that sport event. In other words, it is the minimal stretch of speech reproducing the actual setting of this or that sport event that determines the individual meaning of the word-groups used in speech. Of no less importance is the use of antonym pairs based on contrasting semantic features.

As a result of the abundant application of these elements in sports reports, speech is endowed with additional expressive-emotional-evaluative shades of meaning which add to the impact made on the reader.

\section{Notes:}

1. The meanings of the words kick and shoot adduced in the text above are presented in the Oxford Advanced Learner's Dictionary of Current English with reference to the sphere of sports. Cf. OALDCE, $3^{\text {rd }}$ edition, 1974, Oxford University Press, pp. 464, 790.

\section{References:}

1. Barber, Ch. (1971) Linguistic Change in Present Day English. London: College London.

2. Carter, R.; McCarthy, M. (1988) Vocabulary and Language Teaching. London: Routledge.

3. Cruse, D.A. (2000) Meaning in language: An Introduction to Semantics and Pragmatics. Oxford: OUP.

4. Cruse, D.A. (2001) Lexical Semantics. New York: CUP.

5. Gao, Ch. (2014) A Linguistic Study of Antonymy in English Texts. // Journal of Language Teaching and Research, Vol. 5, N 1, pp. 234-238.

6. Bloomfield, L. (1984) Language. Chicago: University of Chicago Press.

7. Girunyan, G. (2009) English Lexicology (Theoretical Course). Yerevan: Gasprint.

8. Jrbashian, E. (1980) Grakanutyan tesutyun. Yerevan: YSU Press.

9. Minaeva, L.V. (1982) A Manual of English Lexicology. Moscow: MSU Press.

10. Opposite (semantics) Available at: <https://en.wikipedia.org/wiki/Opposite_(semantics)> [Accessed June 2019]. 


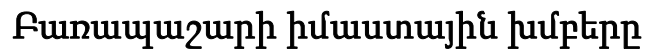

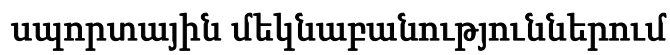

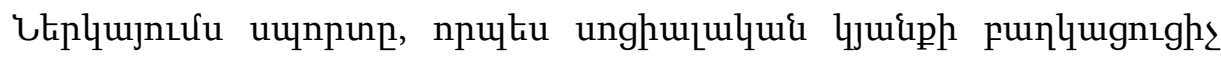

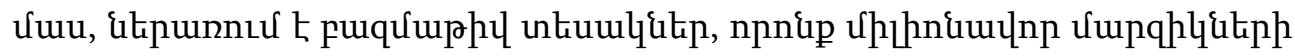

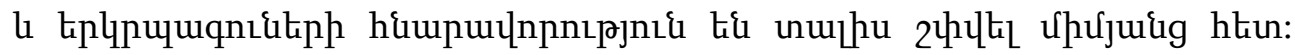

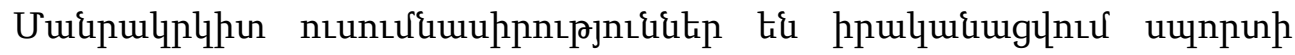

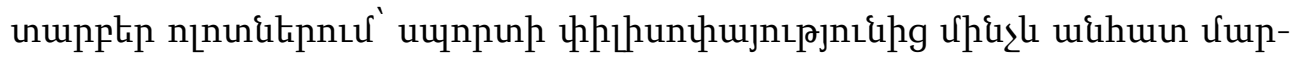

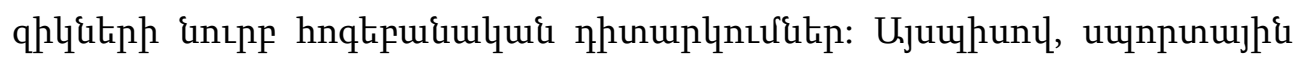

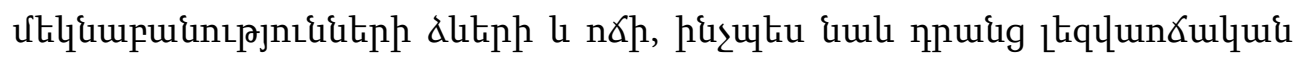

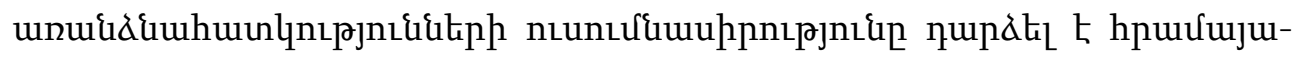

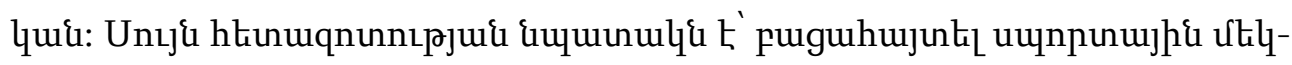

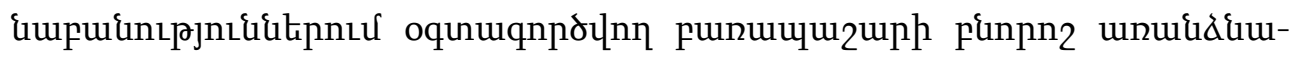

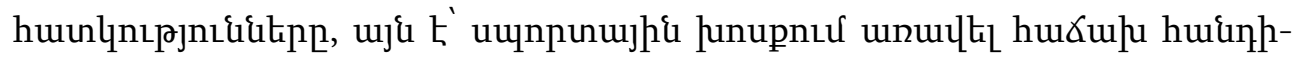

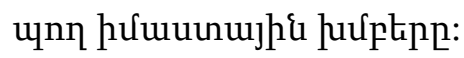

Received by the Editorial Board 20.05.2020

Recommended for publication by the reviewers 14.08.2020

Accepted for print 05.10.2020 